OPEN ACCESS

Edited by:

Miguel Cacho Teixeira,

Universidade de Lisboa, Portugal

Reviewed by:

Paul Cos,

University of Antwerp, Belgium

Paras Jain

Albert Einstein College of Medicine,

USA

Shashank Gupta,

Brown University, USA

${ }^{*}$ Correspondence:

Jaime M. de Santana

jsantana@unb.br

Specialty section:

This article was submitted to

Infectious Diseases,

a section of the journal

Frontiers in Microbiology

Received: 26 December 2016

Accepted: 10 March 2017

Published: 27 March 2017

Citation:

Correa AF, Bastos IMD, Neves $D$, Kipnis A, Junqueira-Kipnis AP and de Santana JM (2017) The Activity of a Hexameric M17

Metallo-Aminopeptidase Is

Associated With Survival

of Mycobacterium tuberculosis.

Front. Microbiol. 8:504.

doi: 10.3389/fmicb.2017.00504

\section{The Activity of a Hexameric M17 Metallo-Aminopeptidase Is Associated With Survival of Mycobacterium tuberculosis}

\author{
Andre F. Correa1,2, Izabela M. D. Bastos ${ }^{1}$, David Neves ${ }^{1}$, Andre Kipnis ${ }^{2}$, \\ Ana P. Junqueira-Kipnis ${ }^{2}$ and Jaime M. de Santana ${ }^{1 *}$
}

'Laboratório de Interação Patógeno-Hospedeiro, Instituto de Biologia, Universidade de Brasília, Brasilia, Brazil, ${ }^{2}$ Instituto de Patologia Tropical e Saúde Pública, Universidade Federal de Goiás, Goiânia, Brazil

Mycobacterium tuberculosis is one of the most prevalent human pathogens causing millions of deaths in the last years. Moreover, tuberculosis (TB) treatment has become increasingly challenging owing to the emergence of multidrug resistant $M$. tuberculosis strains. Thus, there is an immediate need for the development of new anti-TB drugs. Proteases appear to be a promising approach and may lead to shortened and effective treatments for drug-resistant TB. Although the $M$. tuberculosis genome predicts more than 100 genes encoding proteases, only a few of them have been studied. Aminopeptidases constitute a set of proteases that selectively remove amino acids from the $\mathrm{N}$-terminus of proteins and peptides and may act as virulence factors, essential for survival and maintenance of many microbial pathogens. Here, we characterized a leucine aminopeptidase of $M$. tuberculosis (MtLAP) as a cytosolic oligomeric metalloaminopeptidase. Molecular and enzymatic properties lead us to classify MtLAP as a typical member of the peptidase family M17. Furthermore, the aminopeptidase inhibitor bestatin strongly inhibited MtLAP activity, in vitro $M$. tuberculosis growth and macrophage infection. In murine model of TB, bestatin treatment reduced bacterial burden and lesion in the lungs of infected mice. Thus, our data suggest that MtLAP participates in important metabolic pathways of $M$. tuberculosis necessary for its survival and virulence and consequently may be a promising target for new anti-TB drugs.

Keywords: MtLAP, proteases, tuberculosis, leucine aminopeptidase, M17 metallo protease, bestatin

\section{INTRODUCTION}

Mycobacterium tuberculosis is one of the most prevalent human pathogens. In the last year, an estimated 9.6 million people developed tuberculosis (TB) leading to 1.4 million deaths (WHO, 2016). In the last years, $\mathrm{TB}$ treatment has become increasingly challenging owing to the emergence of multidrug-resistant M. tuberculosis strains (Günther, 2014). Thus, there is an immediate need for the development of new drugs that target novel biological pathways to avoid cross-resistance. For instance, $M$. tuberculosis proteases appear to be a promising approach and may lead to shortened and effective treatments for drug-resistant TB (Roberts et al., 2013). Although the M. tuberculosis genome predicts more than 100 genes encoding proteases, only a few of them have been studied. 
Proteolysis plays a central role in the biology of pathogens since it has been involved in their invasion, migration, acquisition of nutrients and evasion from inflammatory and immune responses.

Many studies have shown the importance of these proteins in bacterial (Ingmer and Brøndsted, 2009; Kennan et al., 2010; Frees et al., 2013), fungal (Xu et al., 2006; Yike, 2011), protozoan (Grellier et al., 2001; Klemba and Goldberg, 2002; Bastos et al., 2010; Suarez et al., 2013) and viral infections (Flexner et al., 2005; Konvalinka et al., 2015). Aminopeptidases constitute a diverse set of proteolytic enzymes that selectively remove amino acids from the $\mathrm{N}$-terminus of proteins and peptides. Due to this kind of activity, aminopeptidases mediate, for example, the release of free amino acids to be used as a nitrogen source (Gonzales and Robert-Baudouy, 1996). Alternatively, these enzymes accomplish key steps in many activation or inactivation pathways by liberating amino acids from the N-terminus of self-derived proteins (Savijoki et al., 2006; Hearn et al., 2009; Naamati et al., 2009). Therefore, aminopeptidases act as virulence factors, essential for survival and maintenance of many microbial pathogens (Zhang et al., 2007; Skinner-Adams et al., 2010; Bhosale et al., 2012).

Aminopeptidases could be grouped according to the chemical nature of the catalytic site and substrate specificity (Rawlings and Barrett, 1993). One of the most intensively studied set of aminopeptidases is the hexameric leucine aminopeptidases (LAPs), which belongs to the M17 family of metalloproteases (Matsui et al., 2006). Found in animals, plants and microorganisms, LAPs play important roles in diverse physiological processes such as activation or inactivation of peptides, including neuropeptides and hormone peptides (Flexner et al., 2005), and trimming of MHC class I associated peptides in the endoplasmic reticulum (Naamati et al., 2009). In microbes, M17 LAPs have a function in proteolysis and have also acquired the ability to bind DNA (Matsui et al., 2006). Studies of M17 family members have increased in the last years due to their emergence as potential candidates for vaccine development and drug target in a number of parasitic and bacterial diseases (Acosta et al., 2008; Marcilla et al., 2008; McGowan et al., 2010; Carroll et al., 2012; Lee et al., 2015).

Leucine aminopeptidase is conserved and predicted to be essential for in vivo survival and pathogenicity of mycobacteria such as M. tuberculosis, M. leprae, M. bovis, and M. avium paratuberculosis (Ribeiro-Guimarães and Pessolani, 2007). Furthermore, there is increasing evidence that proteases are potential drug targets against bacterial infections such as tuberculosis (Roberts et al., 2013).

Herein, we describe the characterization of a LAPs of M. tuberculosis (MtLAP) as a cytosolic hexameric metalloaminopeptidase. Moreover, molecular and enzymatic properties, such as susceptibility to inhibitors, lead us to classify MtLAP as a typical member of the peptidase family M17. The aminopeptidase inhibitor bestatin strongly inhibited MtLAP activity; in vitro M. tuberculosis growth, macrophage infection and it also reduced bacterial burden and lungs lesions in murine model of tuberculosis. Thus, our data suggest that MtLAP participates in important metabolic pathways of $M$. tuberculosis necessary for its survival and virulence and consequently may be a promising drug target.

\section{MATERIALS AND METHODS}

\section{Bacterial Strains and Growth Conditions}

Mycobacterium tuberculosis $\mathrm{H} 37 \mathrm{Rv}$ was grown at $37^{\circ} \mathrm{C}$ in Middlebrook $7 \mathrm{H} 9$ broth supplemented with $10 \%$ oleic acidalbumin-dextrose (OAD), 0.5\% glycerol, and 0.05\% Tween 80 . Escherichia coli strain XL10-gold (Stratagene) was used for cloning and plasmid propagation. The recombinant protein was expressed in E. coli BL21 DE3 strain (Invitrogen). E. coli strains were maintained in Luria-Bertani (LB). Plasmid selection was performed with addition of kanamycin $(50 \mu \mathrm{g} / \mathrm{mL})$ or ampicillin $(100 \mu \mathrm{g} / \mathrm{mL})$ to the medium. Solid medium was prepared by the addition of $1.5 \%$ agar to the LB medium or $7 \mathrm{H} 11$ supplemented with $10 \%$ OAD.

\section{Mice}

Male specific-pathogen-free $\mathrm{C} 57 \mathrm{BL} / 6$ or interferon-gamma knockout (IFN- $\gamma$ KO) mice aged 4-8 weeks, obtained from the animal care facility of the Institute of Tropical Pathology and Public Health at Federal University of Goiás (UFG), were maintained in isolators in class 3 biosafety level (BL3) cabinets with water and food provided ad libitum. Temperature was monitored and maintained around $22^{\circ} \mathrm{C}$, relative humidity $60 \%$, and $12 \mathrm{~h}$ light/dark cycles. The use of mice was conducted in accordance with the guidelines of the Brazilian Society of Animal Science Laboratory (SBCAL/COBEA). This study was carried out in accordance with the recommendations of Committee on the Ethics of Animal Experiments of Universidade Federal de Goiás (Approved protocol: 027/14).

\section{Molecular Cloning and Recombinant Protein Expression}

Mycobacterium tuberculosis LAP gene $\left(\mathrm{Rv} 2213^{1}\right)$ was subcloned into PCR2.1 TOPO vector (Invitrogen) using a PCR amplified product from the $M$. tuberculosis H37Rv genome. The recombinant PCR2.1 vector was digested to release the gene that was ligated into the pET28a expression vector (Novagen), submitted to DNA sequencing and inserted into the expression host E. coli BL21. Bacteria containing the recombinant expression vector were grown at $37^{\circ} \mathrm{C}$. When the bacterial cells reached $\mathrm{OD}_{600}$ measurements of 0.6 , the expression of the recombinant protein was induced by the addition of isopropyl-beta-D-thiogalactopyranoside (IPTG) to a final concentration of $0.1 \mathrm{mM}$, and the incubation continued at $20^{\circ} \mathrm{C}$ during $16 \mathrm{~h}$. Bacterial cells were collected by centrifugation $(10,000 \times g$ for $5 \mathrm{~min})$, and suspended in $4 \mathrm{~mL}$ of binding buffer (20 mM imidazole, $0.5 \mathrm{M} \mathrm{NaCl}$, and $20 \mathrm{mM}$ Tris- $\mathrm{HCl} \mathrm{pH} 7.9$ ). After sonication, cell lysate was centrifuged $(20,000 \times g$ for $15 \mathrm{~min}$ ), and the supernatant was applied onto a resin column (Novagen) charged with $\mathrm{NiSO}_{4}$ and equilibrated with binding buffer. Proteins were eluted with a concentration gradient of

\footnotetext{
${ }^{1}$ http://genolist.pasteur.fr/TubercuList
} 
imidazole (40-000 $\mathrm{mM})$ and protein concentration of the eluted fractions was determined by Bradford protein assay. The purified MtLAP was dialyzed against Tris- $\mathrm{HCl}$ pH7.5 with $250 \mathrm{mM} \mathrm{NaCl}$ and stored in $50 \%$ glycerol at $-20^{\circ} \mathrm{C}$. The purity of the protein was analyzed by Coomassie-stained 12\% SDS-PAGE.

\section{Western Blot}

$\mathrm{H} 37 \mathrm{Rv}$ lysates and culture filtrate protein (CFP) were prepared as previously described Correa et al. (2014). Bacterial cultures $(200 \mathrm{~mL})$ were grown in Sauton media to late log phase and then pelleted by centrifugation at $2,000 \times g$ for $20 \mathrm{~min}$. Supernatant was transferred to a fresh tube, centrifuged again, and then filtered through a $0.2 \mu \mathrm{m}$ filter unit. Supernatant was concentrated by protein acetone precipitation. Bacterial pellet was used for H37Rv lysates by sonication. Samples were resolved by $12 \%$ SDS-PAGE and transferred to nitrocellulose membranes. Membranes were blocked in 5\% powdered milk in PBS and probed with the anti-MtLAP or anti-Zmp1 polyclonal serum produced in mice, followed by incubation with the anti-mouse IgG-alkaline phosphatase secondary antibody (Sigma-Aldrich). Antigen-antibody complex was detected via BCIP/NBT liquid substrate (Sigma-Aldrich).

\section{Analytical Ultracentrifugation}

Sedimentation velocity experiments were performed using a Beckman XL-I analytical ultracentrifuge and an AN-60 TI rotor (Beckman Coulter). The experiments were carried out at $20^{\circ} \mathrm{C}$ for MtLAP at $18.2 \mu \mathrm{M}$ in $25 \mathrm{mM}$ Tris $\mathrm{pH} 7.5,500 \mathrm{mM}$ $\mathrm{NaCl}$. A volume of $400 \mu \mathrm{L}$ was loaded into $12 \mathrm{~mm}$ path cells and centrifuged at $130,000 \times g(42,000 \mathrm{rpm})$. Scans were recorded every $3 \mathrm{~min}$, overnight, at $280 \mathrm{~nm}$. We used the Sednterp software ${ }^{2}$ to estimate the partial specific volume of the polypeptide chain, $\bar{v}=0.741 \mathrm{~mL} / \mathrm{g}$, the solvent density, $\rho=1.01920 \mathrm{~g} / \mathrm{mL}$, and the solvent viscosity, $\eta=1.0556 \mathrm{mPa} . \mathrm{s}$, at $20^{\circ} \mathrm{C}$. Sedimentation profiles were analyzed by the sizedistribution analysis of Sedfit ${ }^{3}$. In Sedfit, finite element solutions of the Lamm equation for a large number of discrete, independent species, for which a relationship between mass, sedimentation and diffusion coefficients, $s$ and $\mathrm{D}$, is assumed, are combined with a maximum entropy regularization to represent a continuous size-distribution. We used 200 collected sets of data using fitted frictional ratio for sedimentation coefficients comprised between 0 and $45 \mathrm{~S}$ and a 0.68 confidence level.

\section{Assay of Enzyme Activity}

The activity of MtLAP was assayed by incubating $300 \mathrm{ng}$ of the purified enzyme with $20 \mu \mathrm{M}$ of L-Leu-7-amido-4methylcoumarin (Leu-AMC), Met-AMC, Pro-AMC, Arg-AMC, or Asp-AMC (Sigma-Aldrich) in $100 \mu \mathrm{L}$ reaction buffer $(25 \mathrm{mM}$ Tris- $\mathrm{HCl} \mathrm{pH} 7.5$ and $1.5 \mathrm{mM} \mathrm{NiSO}_{4}$ ). Substrate hydrolysis was determined by AMC release measured fluorometrically using SpectraMax M5 Microplate Reader with SoftMax Pro Data Acquisition and Analysis Software (Molecular Devices) as

${ }^{2}$ http://www.jphilo.mailway.com/

${ }^{3}$ http://www.analyticalultracentrifugation.com described previously (Cadavid-Restrepo et al., 2011). Enzyme cation preference was performed using different concentrations of $\mathrm{CaCl}_{2}, \mathrm{CoCl}_{2}, \mathrm{CuSO}_{4}, \mathrm{FeCl}_{2}, \mathrm{MgCl}_{2}, \mathrm{MnCl}_{2}, \mathrm{NiSO}_{4}$, or $\mathrm{ZnSO}_{4}$ in Tris- $\mathrm{HCl} \mathrm{pH} 7.5$ at $25^{\circ} \mathrm{C}$ containing Leu-AMC as substrate. The optimal $\mathrm{pH}$ for activity was determined as described above in $25 \mathrm{mM}$ AMT buffer (25 mM acetic acid-25 mM MES-25 mM Tris- $\mathrm{HCl}$ ) adjusted to $\mathrm{pHs}$ ranging from 5 to 10 . To assess the effect of temperature on MtLAP activity, enzyme reactions took place at temperatures ranging from 10 to $100^{\circ} \mathrm{C}$. The MichaelisMenten constant $(\mathrm{Km})$ of MtLAP were determined according to the hyperbolic regression method using Prism software version 5.03 (GraphPad). The oligomeric structure of the enzyme was evaluated by electrophoresis as described previously (CadavidRestrepo et al., 2011). Briefly, purified protein was subjected to $8 \%$ SDS-PAGE in the presence $0.01 \%$ SDS under non-reducing conditions with or without previous boiling of the sample.

\section{MtLAP Inhibition}

Different concentrations of tosyl-lysylchloromethane (TLCK), bestatin, tosyl phenylalanyl chloromethyl ketone (TPCK), EDTA, L-trans-epoxysuccinylleucylamido-4-guanidino butane (E-64), phenylmethylsulfonyl fluoride (PMSF), 1,10-phenanthroline, leupeptin, or pepstatin A were incubated with $300 \mathrm{ng}$ of purified MtLAP in $100 \mu \mathrm{L}$ reaction buffer for $5 \mathrm{~min}$ at room temperature, before the substrate was added. Enzymatic reactions were monitored as described above. All inhibitors were from Sigma-Aldrich. Bestatin half-maximal inhibitory concentration (IC50) and 95\% confidence interval (CI) were calculated by nonlinear regression log (inhibitor) vs. normalized response with variable slope method.

\section{Effect of Bestatin on M. tuberculosis Growth}

To study the effect of bestatin on $M$. tuberculosis growth, bacterial cultures were adjusted, and 100 CFU were deposited into each well of a 96-well microplate that contained a serial dilution of bestatin, ranging from 1600 to $25 \mu \mathrm{g} / \mathrm{mL}$ in Middlebrook 7H9 supplemented with 10\% OAD, 0.5\% glycerol and $0.05 \%$ Tween 80 . The bestatin 50\% growth inhibitory concentration (GI50) value was determined by non-linear regression log (inhibitor) vs. normalized response with variable slope method.

\section{Alveolar Macrophage Culture}

Alveolar macrophages were obtained from C57BL/6 mice bronchoalveolar lavage (BAL). Mice were euthanized and the pulmonary cavities were opened. Using an 18-gage needle, the trachea was cannulated, and $1.0 \mathrm{~mL}$ of ice-cold $5 \mathrm{mM}$ EDTA in PBS was slowly injected into the lungs and then withdrawn. This procedure was repeated five times and a total of $4 \mathrm{~mL}$ of BAL fluid was collected from each mice. The single-cell suspension was then washed and centrifuged at 1,000 $\times$ g. Red blood cells were lysed upon $5 \mathrm{~min}$ incubation in $2 \mathrm{~mL}$ of Gey's solution $(155 \mathrm{mM}$ $\mathrm{NH}_{4} \mathrm{Cl}$ and $10 \mathrm{mM} \mathrm{KHCO} 3$ ) at room temperature. Macrophages were then washed with PBS and resuspended in RPMI medium 1640 (Gibco) supplemented with 1\% glutamine, 1\% non-essential 


\section{A}

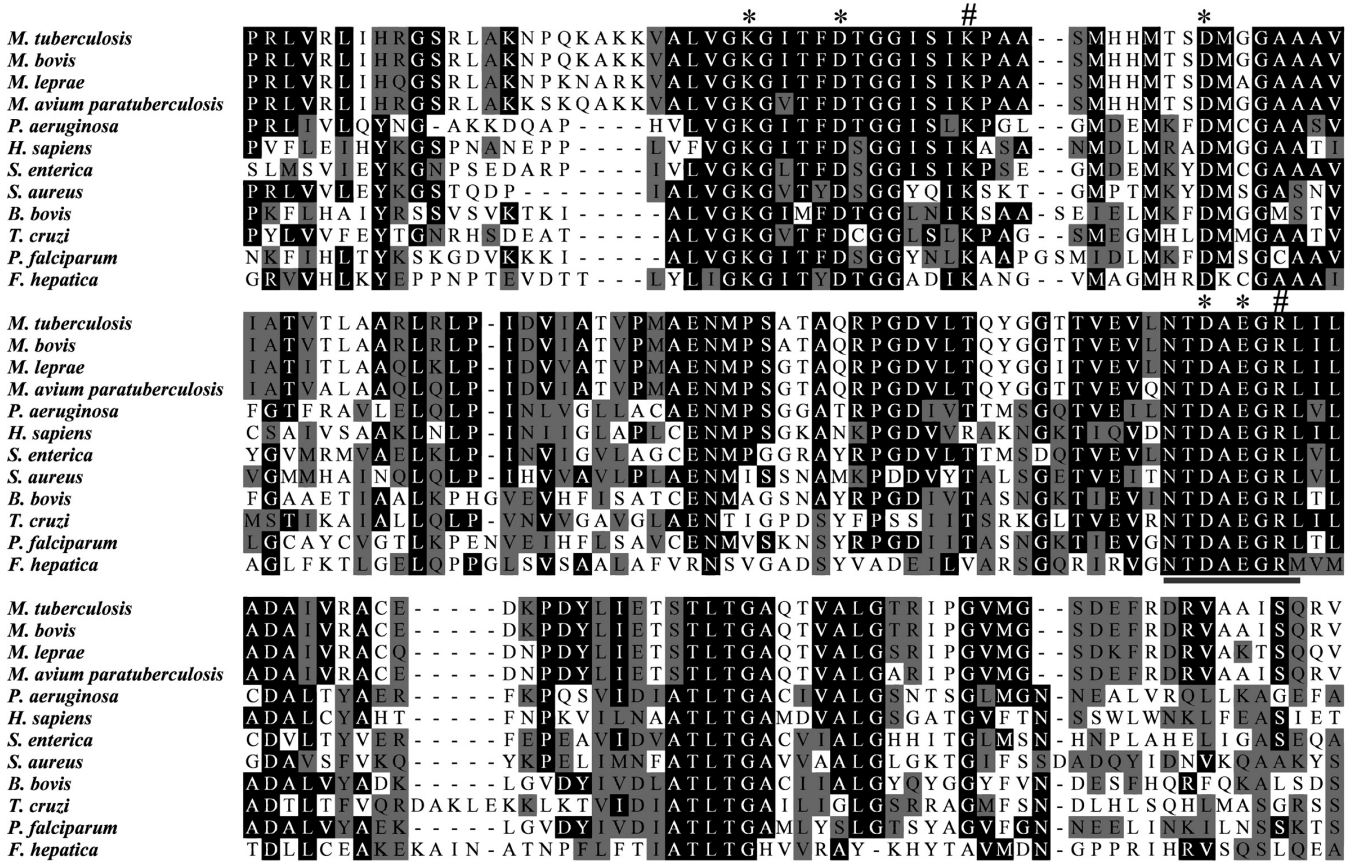

B

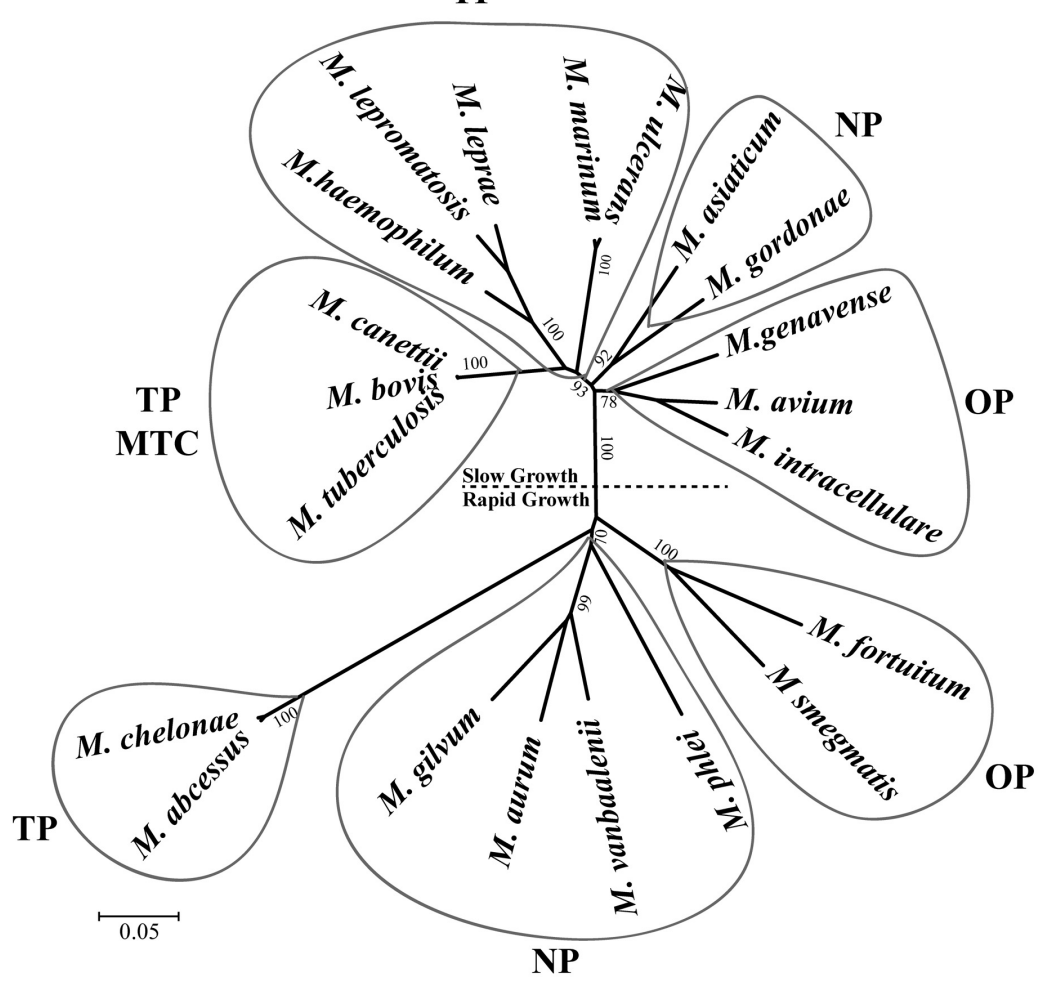

FIGURE 1 | Sequence analysis and phylogenetic relationship of M17 LAPs. (A) Multiple Carboxi-terminal portion amino acid sequence alignments of different LAPs. Amino acid sequences from the conserved C-terminal region of LAPs were aligned by the ClustalX program. Amino acids marked in black show $50 \%$ identity and those in gray show $50 \%$ similarity. Putative metal binding sites $\left(^{*}\right)$, catalytic site (\#), and M17 signature (underlined) are indicated. Sequences were obtained from the protein database of the National Center for Biotechnology Information (NCBI). (B) Phylogenetic relationship of LAP in mycobacterial genus. 21 full length sequences, derived from the non-reduntant (NR) protein database of the NCBI (listed in Experimental Procedures), were aligned by the ClustalX program, and the phylogram generated with the Mega package after 1000 bootstraps inferred using the Neighbor-Joining method. The tree is drawn to scale with branch lengths in the same units as those of the evolutionary distances used to infer the phylogenetic tree. Drawn balloons represent the sequences clusters of true pathogenic (TP), M. tuberculosis Complex (MTC), opportunist pathogens (OP) and non-pathogenic mycobacteria (NP). 
TABLE 1 | Leucine aminopeptidases (LAPs) amino acid sequence identity.

\begin{tabular}{lc}
\hline & \multicolumn{1}{c}{ Identity } \\
\cline { 2 - 2 } Organism & M. tuberculosis \\
\hline M. bovis & 0.996 \\
M. leprae & 0.824 \\
M. avium & 0.805 \\
P. aeruginosa & 0.313 \\
H. sapiens & 0.281 \\
S. enterica & 0.265 \\
S. aureus & 0.258 \\
B. bovis & 0.253 \\
T. cruzi & 0.234 \\
P. falciparum & 0.211 \\
F. hepatica & 0.149 \\
\hline
\end{tabular}

amino acids, $1 \mathrm{mM}$ sodium pyruvate, $1 \%$ penicillin-streptomycin and $10 \%$ FBS.

\section{M. tuberculosis Infected Macrophage Treatment Assay}

The alveolar macrophages were plated in 96 well plates (100 $\mathrm{\mu L} /$ well) at $10^{6}$ cells/well and incubated for $24 \mathrm{~h}$ at $37^{\circ} \mathrm{C}$. Macrophage monolayers were then washed and incubated with $100 \mu \mathrm{L}$ infection media (RPMI medium 1640 supplemented with $1 \%$ glutamine, $1 \%$ non-essential amino acids, $1 \mathrm{mM}$ sodium pyruvate, $10 \% \mathrm{FBS}$ ) containing $5 \times 10^{6} \mathrm{CFU}$ of $M$. tuberculosis $\mathrm{H} 37 \mathrm{Rv}(\mathrm{MOI}=5)$ at $37^{\circ} \mathrm{C}$ under $\mathrm{CO}_{2}$ for $3 \mathrm{~h}$. Then the cells were washed twice with warm PBS to remove extracellular bacteria and supplemented with RPMI free of antibiotics and containing a range of 0,100 , or $200 \mu \mathrm{g} / \mathrm{mL}$ of bestatin. Forty-eight hours after infection, media was aspirated from infected macrophage wells, and $100 \mu \mathrm{L}$ of ice-cold sterile lysis solution (0.05\% SDS, $\mathrm{w} / \mathrm{v}$ in $\mathrm{H}_{2} \mathrm{O}$ ) was added to each well. The lysates were transferred to a new 96 well plate for serial dilutions. Triplicate wells were plated on 7H11 agar supplemented with OAD. The plates were cultured in a $\mathrm{CO}_{2}$ incubator for 3-4 weeks and the number of CFUs counted.

\section{M. tuberculosis Infection and In vivo Bestatin Treatment}

IFN- $\gamma$ knockout mice were intranasally infected with $10^{4}$ M. tuberculosis $\mathrm{H} 37 \mathrm{Rv}$ and treatment was performed as previously described (Lenaerts et al., 2003). In brief, 1 day post infection, three mice were euthanized by cervical dislocation to verify bacterial uptake per mouse. Each treated group consisted of four mice. Treatment was started 18 days after infection and lasted up to 28 days post infection. Another three infected mice were euthanized to determine the bacterial load at the beginning of the treatment (day 18 post infection). Lyophilized bestatin was dissolved in PBS and $100 \mu \mathrm{L}$ administered by intranasal instillation in eight treatments for 5 days/week at $1 \mathrm{mg} / \mathrm{kg}$ of body weight while Isoniazid (INH) was administered at $25 \mathrm{mg} / \mathrm{kg}$ as positive control. A negative control group of infected but untreated mice received $100 \mu \mathrm{L}$ of intranasal PBS. After the cessation of treatment (day 28 post infection), viable bacteria in the mice lungs were evaluated. Right and left cranial lung lobes were removed and homogenized in PBS containing 0.05\% Tween 80, and tissue homogenates were serially diluted in PBS and plated in duplicate onto Middlebrook $7 \mathrm{H} 11$ agar. Colonies were counted after $3-4$ weeks of incubation at $37^{\circ} \mathrm{C}$ in a $5 \% \mathrm{CO}_{2}$ incubator.

\section{Histopathology}

The caudal left lung lobe was excised from all animals, stored in $10 \%$ formalin, then embedded in paraffin and sections were prepared and stained with hematoxylin and eosin (H\&E). Lung lesions were determined using the measurement tool in the AxioVision software (Carl Zeiss). Total lesion area was calculated by the sum of all areas of lesions in a lung section per mouse.

\section{Statistical Analysis}

Statistical significance between groups was determined by the two-tailed unpaired Student's $t$-test or One-way ANOVA with Dunnett or Tukey post-test using Prism software version 5.03 (GraphPad).

\section{RESULTS}

\section{LAP Is Conserved in Pathogenic Mycobacteria}

The sequencing of $M$. tuberculosis $\mathrm{H} 37 \mathrm{Rv}$ genome revealed a small number of genes coding for putative peptidases that mediate aminopeptidolytic activities https://merops.sanger.ac. uk/index.shtml. We identified only one copy of a putative LAP gene $\left(\operatorname{Rv} 2213^{4}\right)$, which has thus far not been characterized. Rv2213 is an open reading frame (ORF) that encodes a protein of 515 amino acids. Multiple amino acid sequence alignments revealed that the $\mathrm{C}$-terminal conserved region presents the typical signature sequence NTDAEGRL of the M17 family (Burley et al., 1990) as well as multiple conserved amino acids within predicted functional domains for metal binding and catalytic activity conserved across different taxa (Figure 1A). LAP of $M$. tuberculosis shares high identity with other pathogenic mycobacterial LAPs, over $80 \%$ with $M$. leprae, M. bovis, and M. avium paratuberculosis. Although it contains conserved functional domains, MtLAP shares less than 32\% identity with species out of the Mycobacterium genus, diverging from LAPs from other bacteria, protozoa and higher eukaryotes, including only $28.1 \%$ identity with human LAP (Figure 1A and Table 1). The phylogenetic analysis of LAP from the Mycobacterium genus shows a relationship between LAP sequence similarities and bacterial physiology and pathogenesis. The phylogenetic tree shows divergent groups of proteins that cluster according to the bacterial rate of growth and pathogenicity with a strong bootstrap support (Figure 1B). Sequences are divided in two defined clades; one branch includes slow growing mycobacteria and the other cluster, the rapid growers. Moreover, for slow and rapid growing mycobacteria, LAP sequences are divided into

${ }^{4}$ http://tuberculist.epfl.ch 
A

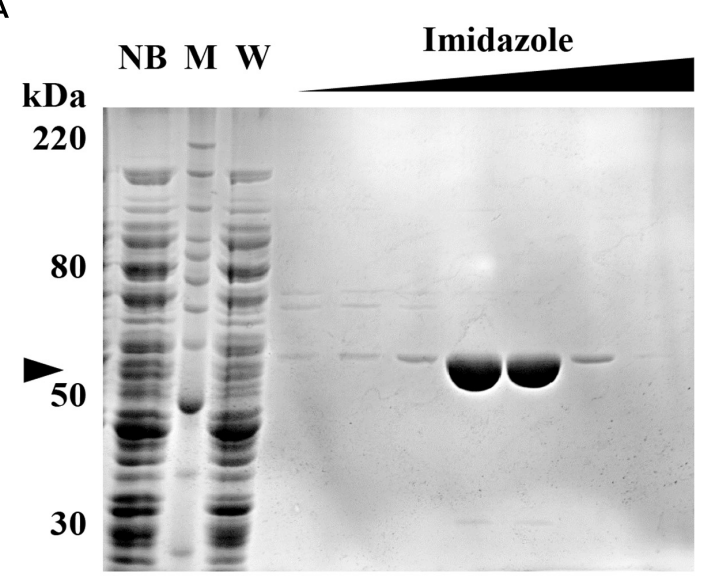

B

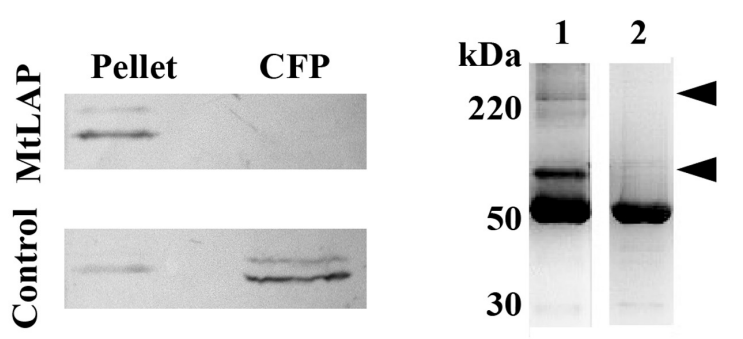

FIGURE 2 | Purification and subcellular localization of $M$. tuberculosis LAP (MtLAP). (A) Purification of recombinant MtLAP: IPTG-induced MtLAP was purified by nickel affinity chromatography. Aliquots of resin unbound fraction (NB), molecular mass marker (M), wash (W) and elution with increasing imidazole concentration were submitted to $12 \%$ reducing SDS-PAGE and the gel stained with Coomassie brilliant blue. Arrowhead indicates LAP position at $55 \mathrm{kDa}$. (B) Localization of MtLAP by immunoblot analysis (up) and control of non-specific lysis (down). Lanes: H37Rv pellet total cell lysate (Pellet) and H37Rv culture filtrate proteins (CFP) were probed with MtLAP or Zmp1 (Control) polyclonal mouse antiserum. (C) Analysis of MtLAP oligomeric state: the recombinant enzyme was subjected to $8 \%$ SDS-PAGE in the presence of only $0.01 \%$ SDS, previously boiled (2) or not (1). Arrowheads indicate $100 \mathrm{kDa}$ and over $220 \mathrm{kDa}$ oligomeric states.

three groups. One branch includes true pathogenic mycobacteria (TP), another branch groups opportunistic bacteria (OP) and the other branch contains non-pathogenic mycobacteria (NP). Similarly, true pathogenic slow growing mycobacteria belong to the M. tuberculosis complex (MTC) grouped together in a very close phylogenetic clade (Figure 1B). These findings suggest that MtLAP may be involved in physiological and pathogenicity processes in tuberculosis, thus predicted to be essential for in vivo survival and pathogenicity (Ribeiro-Guimarães and Pessolani, 2007).

\section{MtLAP Is an Oligomeric Cytosolic Protein}

To establish the kinetic parameters of MtLAP, the Mycobacterium tuberculosis gene Rv2213 was cloned into the prokaryotic

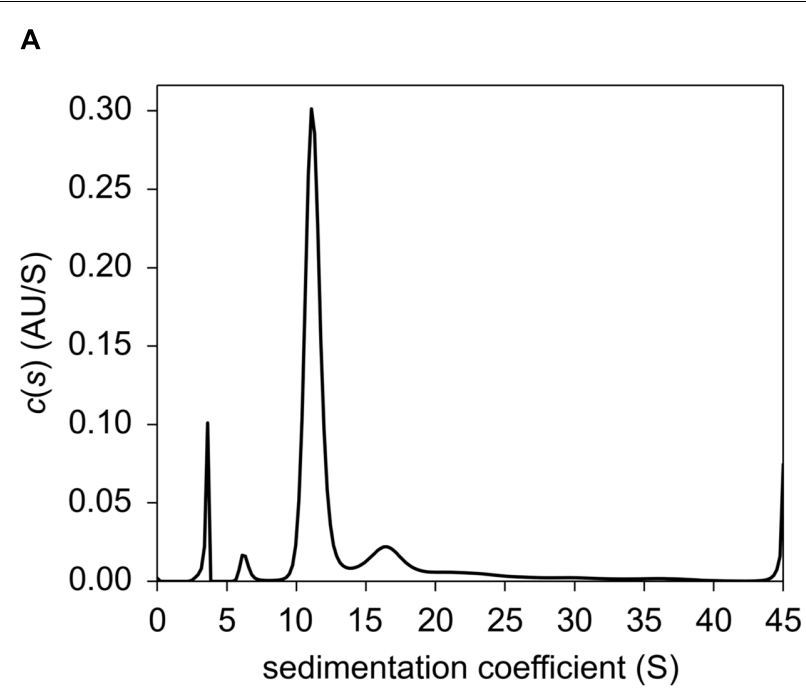

B

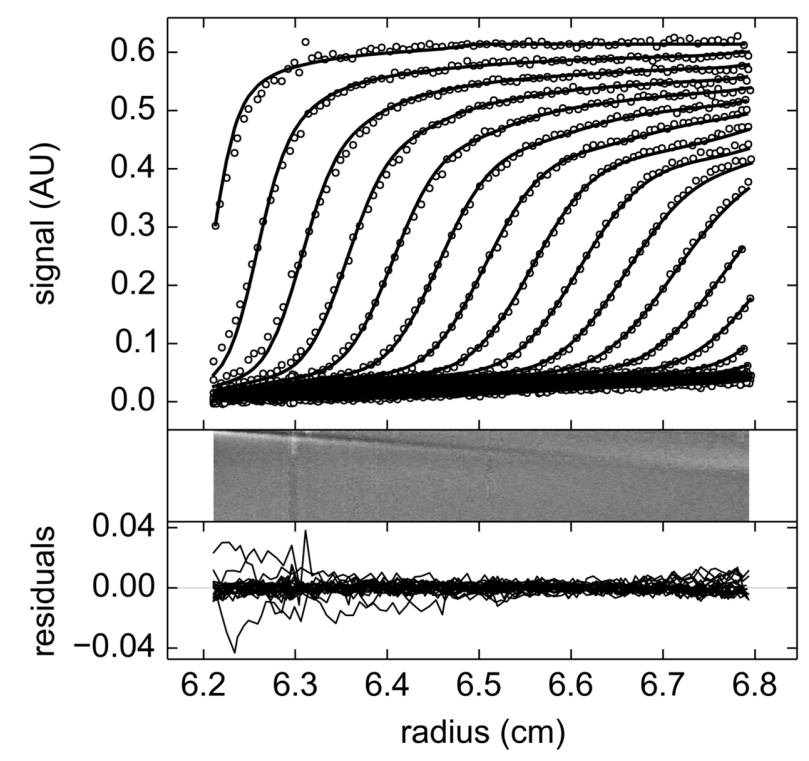

FIGURE 3 | Sedimentation velocity experiments of purified MtLAP. (A) MtLAP experimental sedimentation profile at $18.2 \mu \mathrm{M}$ in $25 \mathrm{mM}$ Tris $\mathrm{pH}$ $7.5,500 \mathrm{mM} \mathrm{NaCl}$ obtained at $280 \mathrm{~nm}$ at $130,000 \times \mathrm{g}$, at $20^{\circ} \mathrm{C}$, in $12 \mathrm{~mm}$ cell and their modeled profiles with the c(s) analysis (upper panel). The corresponding residual, superposition of the differences between the experimental and fitted curves (lower panel). (B) Result of the $\mathrm{c}(\mathrm{s})$ analysis for LAP at $18.2 \mu \mathrm{M}$.

expression vector pET28a. The recombinant protein was expressed and purified by nickel affinity chromatography under non-denaturing conditions with increasing imidazole concentrations. SDS-PAGE analysis revealed a strong band, with high purity, eluted with imidazole at a concentration higher than $200 \mathrm{mM}$, corresponding to the expected protein molecular mass of approximately $55 \mathrm{kDa}$ (Figure 2A). For detection and identification of the native protein, anti-MtLAP polyclonal serum was produced in mice. We verified by western blot the presence of the protein in the $\mathrm{H} 37 \mathrm{Rv}$ cell fraction extract, but 
$\mathbf{A}$

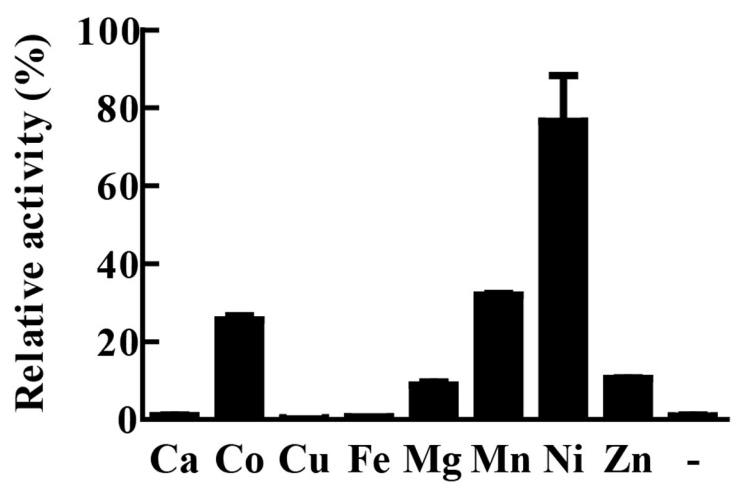

C

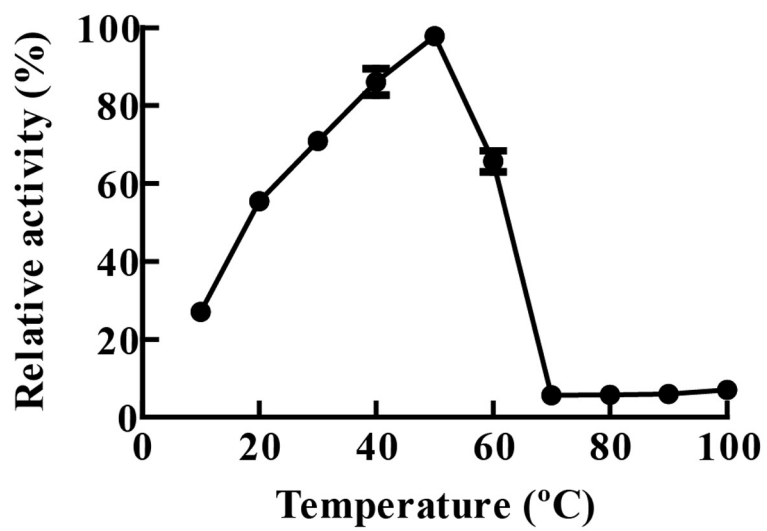

B

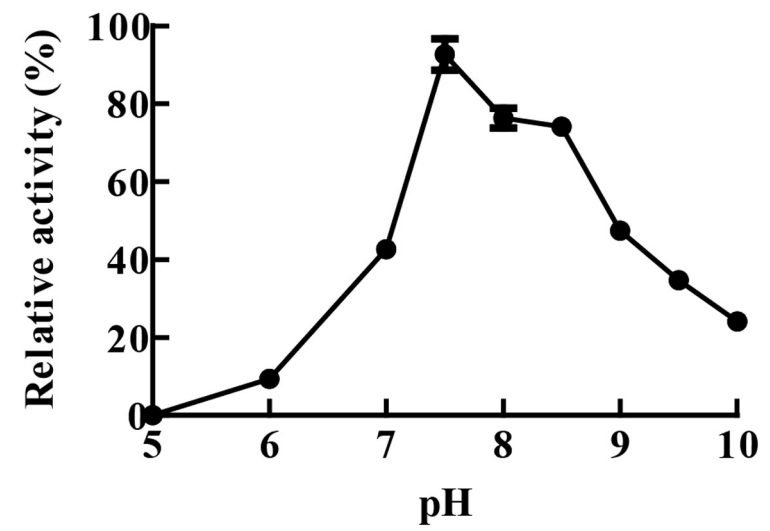

D

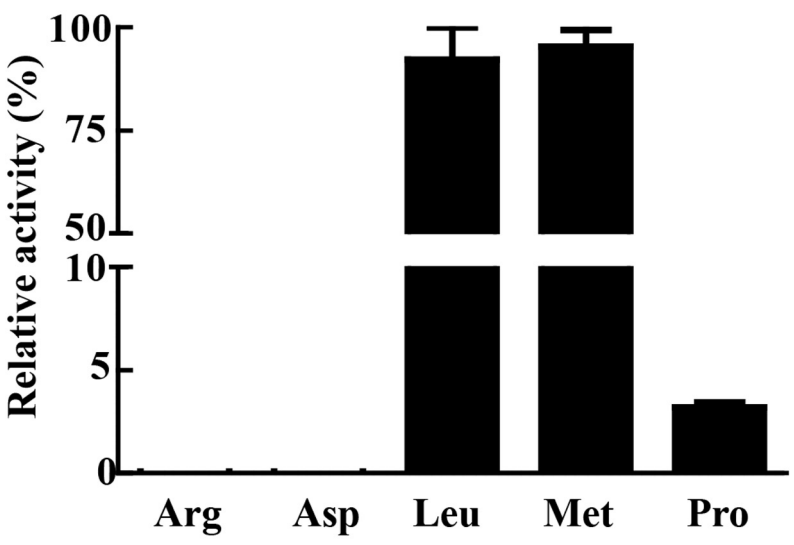

FIGURE 4 | Biochemical characterization of MtLAP. (A) Effect of metal ions on MtLAP activity: Activity was assayed in the presence of different metal ions (1.5 mM concentration) and no metal addition (-). (B) Effects of pH on MtLAP activity: the experiments were performed over the pH range 5-10 in $25 \mathrm{mM}$ AMT buffer with $1.5 \mathrm{mM} \mathrm{NiSO}_{4}$ and $20 \mu \mathrm{M}$ substrate. (C) Effects of temperature on MtLAP activity: the experiments were carried out in $25 \mathrm{mM}$ Tris- $\mathrm{HCl}$ buffer pH 7.5 over a temperature range of $10-100{ }^{\circ} \mathrm{C}$ with $1.5 \mathrm{mM} \mathrm{NiSO}_{4}$ and $20 \mu \mathrm{M}$ substrate. (D) Activity of MtLAP against different amino acids: the experiments were carried out in $25 \mathrm{mM}$ Tris- $\mathrm{HCl}$ buffer $\mathrm{pH} 7.5$ with $1.5 \mathrm{mM} \mathrm{NiSO}_{4}$ and $20 \mu \mathrm{M}$ of each indicate substrate. Data shown represent mean \pm SEM, relative to maximal activity obtained, $n=3$.

not in the culture supernatant (CFP, Figure 2B). To confirm that MtLAP was not released to the supernatant, mycobacterial metalloprotease $\mathrm{Zmp}$, previously described as a secreted protein (Master et al., 2008; Correa et al., 2014), was detected in the same culture supernatant preparations (Figure 2B). Since LAPs exist naturally as oligomeric-dependent active proteases (Matsui et al., 2006), we decide to test MtLAP oligomerization. Therefore, non-boiled nor reduced purified protein was subjected to $8 \%$ SDS-PAGE in the presence of $0.01 \%$ SDS. Bands about $100 \mathrm{kDa}$ and over $220 \mathrm{kDa}$ were detected indicating an oligomeric protein complex, although the $55 \mathrm{kDa}$ monomer was predominant in gel (Figure 2C, lane 1). Sample boiling resulted in complete monomerization of MtLAP (Figure 2C, lane 2).

\section{MtLAP Assembles into a Homohexamer}

The results obtained from sedimentation velocity experiments corroborate the calibrated exclusion size chromatography findings. The experimental and fitted sedimentation velocity profile of MtLAP (Figure 3A) obtained at $18.2 \mu \mathrm{M}$ shows a major species, approximately $70 \%$ of the signal, that sediments at $11.2 \mathrm{~S}\left(\mathrm{~S}_{20, w}=12.6 \mathrm{~S}\right)$. The $s$-value is directly related to the molar mass $(M)$ and the Stokes radius $\left(R_{\mathrm{S}}\right)$ of the particle. The combination of the $s$-values with $\mathrm{R}_{S}=5.9 \mathrm{~nm}$ estimated from calibrated size exclusion chromatography gives an estimate for the MtLAP complex of $M=323 \mathrm{kDa}$, which is close to the expected molecular mass for a hexamer $(334.4 \mathrm{kDa})$. Considering a hexamer, the $R_{S}$ value corresponds to a frictional ratio of 1.30 , a value close to 1.25 that relates to globular proteins. It suggests that the MtLAP hexamer has a globular shape. Larger species were also detected but a well-defined peak was difficult to identify. The larger species most probably represents aggregates due to sample aging and also to the fact that MtLAP was prone to precipitate even in high ionic strength buffers. The smaller peaks correspond to only less than $8 \%$ of the signal and give estimated masses of 64 and $140 \mathrm{kDa}$, close to the expected mass of a monomer and a dimmer, respectively (Figure 3B). 


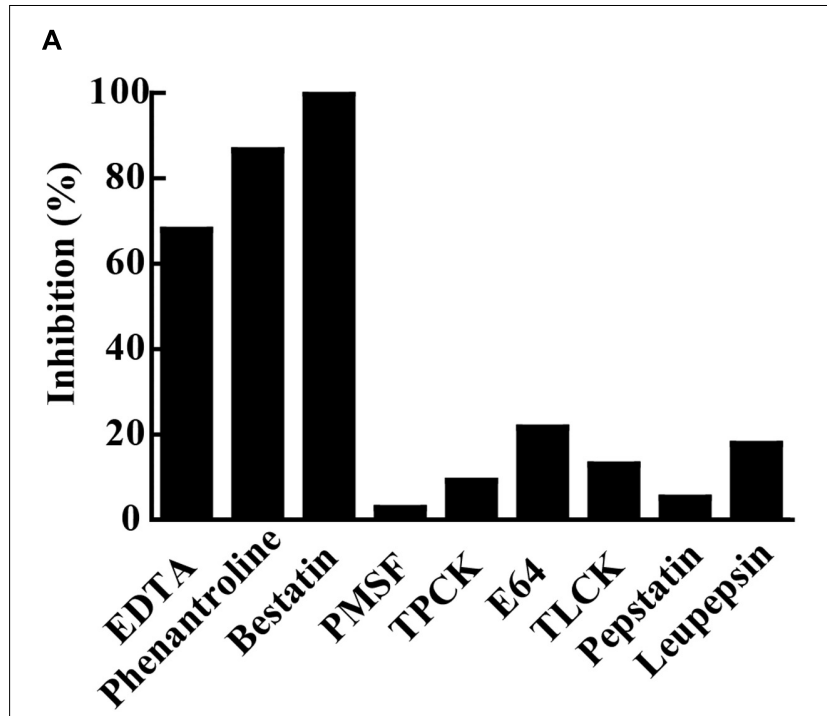

B

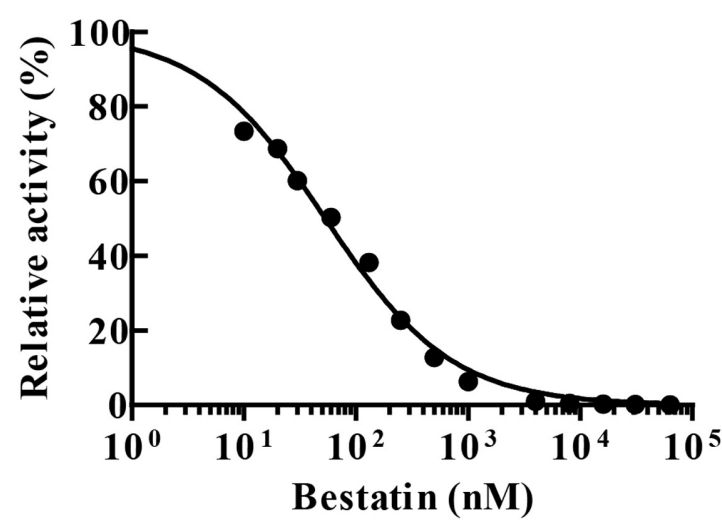

FIGURE 5 | MtLAP inhibition pattern. (A) Effect of different inhibitors on the activity of MtLAP: the experiments were performed in $25 \mathrm{mM}$ Tris- $\mathrm{HCl}$ buffer $\mathrm{pH} 7.5$ with $1.5 \mathrm{mM} \mathrm{NiSO}_{4}, 20 \mu \mathrm{M}$ of Leu-AMC and different inhibitors (10 mM EDTA, 10 mM phenantroline, $30 \mu \mathrm{M}$ bestatin, $5 \mathrm{mM}$ PMSF, $100 \mu \mathrm{M}$ TPCK, $5 \mu \mathrm{M}$ E64, $500 \mu \mathrm{M}$ TLCK, $25 \mu \mathrm{M}$ pepstatin A and $100 \mu \mathrm{M}$ leupepsin). Data represent \% of the activity measured without inhibitors. (B) Bestatin inhibits the enzymatic activity of MtLAP in a dose-dependent manner: the experiments were carried out by pre-incubation of MtLAP with different concentrations of bestatin. Curve fit by non-linear regression log (inhibitor) vs. normalized response with variable slope method.

The presence of these smaller forms may be related to the high salt concentration in the buffer. These data clearly indicate that active MtLAP is an oligomeric protein formed by six monomers.

\section{LAP of M. tuberculosis Is a Metal Dependent Protease}

The activity of recombinant MtLAP was determined by measuring the fluorescence of AMC (7-amido-4methylcoumarin) released by hydrolysis of the enzyme substrate Leu-AMC. However, in the initial assays, no MtLAP activity was observed when the enzyme was incubated with substrate in Tris-buffer in the absence of metal ions. As MtLAP belongs to the metallo aminopeptidase M17 family, that has a broad range of preferences for metal ions, we decided to test MtLAP metal dependence. The enzyme did show activity when the assay was conducted in the presence of metal ions including $\mathrm{Co}^{2+}$, $\mathrm{Mg}^{2+}, \mathrm{Mn}^{2+}, \mathrm{Ni}^{2+}$, and $\mathrm{Zn}^{2+}$. Conversely, $\mathrm{Ca}^{2+}, \mathrm{Cu}^{2+}$, and $\mathrm{Fe}^{2+}$ could not activate MtLAP. The maximum activity was observed in the presence of $1.5 \mathrm{mM} \mathrm{Ni}^{2+}$, followed by $\mathrm{Mn}^{2+}$, $\mathrm{Co}^{2+}, \mathrm{Zn}^{2+}$, and $\mathrm{Mg}^{2+}$ (Figure 4A). Regarding $\mathrm{pH}$ dependence, its optimal activity was observed at $\mathrm{pH}$ 7.5. Although at acidic pHs the enzyme rapidly loses activity and no substrate cleavage was observed at $\mathrm{pH} 5$, the enzyme was resistant to alkaline environment displaying about 50 and $25 \%$ of its maximal activity at pH 9 and 10, respectively (Figure 4B). The activity of MtLAP was determined at different temperatures in the range of $10-$ $100^{\circ} \mathrm{C}$. At $37^{\circ} \mathrm{C}$, the enzyme showed $70.78 \%$ of its maximal activity measured at $50^{\circ} \mathrm{C}$ (Figure $4 \mathrm{C}$ ). To assess the enzyme substrate preference, MtLAP was incubated with aminopeptidase substrates (Figure 4D). Calculated $K_{m}$ values are $69.4 \pm 3.6 \mu \mathrm{M}$ for Leu-AMC, $61.8 \pm 4.4 \mu \mathrm{M}$ and $344.8 \pm 49.2 \mu \mathrm{M}$ for MetAMC and Pro-AMC, respectively (Supplementary Figure 1). The enzyme showed maximal activity on substrates with hydrophobic amino acids leucine and methionine. Low activity was observed with the non-polar cyclic amino acid proline based substrate. No cleavage was detected on substrates with charged side chains containing arginine and aspartic amino acid residues.

\section{MtLAP Inhibition Pattern}

Enzyme hydrolytic activity was not sensitive to the classical serine (PMSF, TLCK or TPCK) and cysteine (E-64) protease inhibitors. The enzyme was not inhibited by leupeptin, an inhibitor of cysteine/serine/threonine proteases, nor by pepstatin A that inhibits aspartyl proteases. The chelating agents 1,10phenanthroline and EDTA inactivated 86.5 and $68 \%$ of the enzyme activity, respectively. Furthermore, the enzymatic activity of MtLAP on Leu-AMC was completely inhibited by $30 \mu \mathrm{M}$ bestatin (Figure 5A). Since bestatin is a potent inhibitor of LAPs, we assayed its inhibition on MtLAP activity in a range of $0.01-100 \mu \mathrm{M}$ using Leu-AMC as a substrate (Figure 5B). As a result, the calculated $\mathrm{IC}_{50}$ was $53.78 \mathrm{nM}$ as shown in Figure 5B with $95 \%$ CI of 46.44-62.28 nM.

\section{Bestatin Inhibits M. tuberculosis Growth in In vitro and Ex vivo}

Since bestatin is efficient at inhibiting MtLAP activity, we asked if it could constrain M. tuberculosis growth. To address this question, we cultivated the bacteria in liquid media with different concentrations of bestatin and measured CFUs. At day seven of culture, a dose-dependent manner inhibition of $M$. tuberculosis growth was observed (Figure 6A). Bestatin shows a 50\% growth inhibitory concentration value (GI50) of $174.2 \mu \mathrm{g} / \mathrm{mL}$ (95\% CI 143.1-212.0 $\mu \mathrm{g} / \mathrm{mL})$. We next examined the effect of bestatin on $M$. tuberculosis survival inside macrophages. The bestatin treatment done after $M$. tuberculosis alveolar macrophages infection showed a significant dose-dependent reduction in 
A

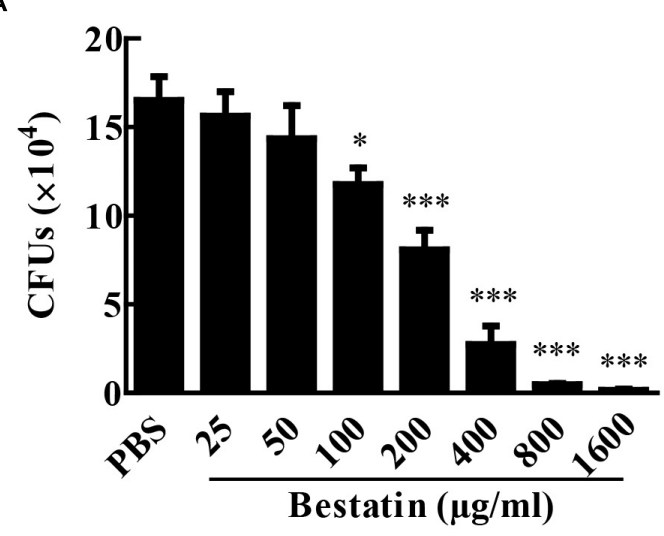

B

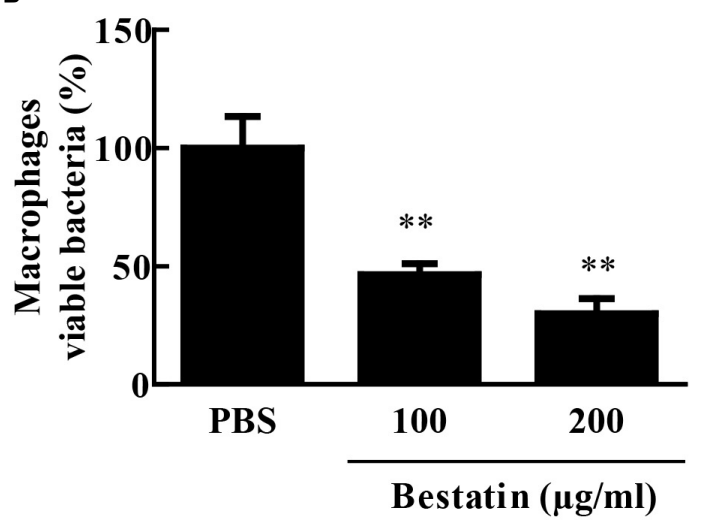

FIGURE 6 | Bestatin inhibits growth of $\boldsymbol{M}$. tuberculosis in vitro and during macrophage infection. (A) Bestatin inhibits the growth of $M$. tuberculosis in vitro in a dose-dependent manner: M. tuberculosis was incubated with or without (PBS) different concentrations of bestatin at $37^{\circ} \mathrm{C}$, and growth was monitored 7 days after addition of the inhibitor by plating serial dilution of culture and counting CFUs. (B) M. tuberculosis survival in macrophages: After macrophage infection, bestatin or PBS was added to the culture and viable $M$. tuberculosis was determined by CFU counting relative to the PBS group $48 \mathrm{~h}$ after treatment. Data shown represent mean \pm SEM, $\mathrm{n}=3$. ${ }^{*} p<0.05 ;{ }^{* *} p<0.01$; ${ }^{* *} p<0.001$; difference from PBS group by One-way ANOVA with Dunnett post test.

colony counts. Compared to PBS infection control, $29.8 \%$ of the mycobacteria were recovered using $200 \mu \mathrm{g} / \mathrm{mL}$ of inhibitor and $46.4 \%$ of the bacteria were viable using bestatin at $100 \mu \mathrm{g} / \mathrm{mL}$ (Figure 6B). Those results suggest that the activity of LAP may be essential for $M$. tuberculosis survival and virulence.

\section{Bestatin Reduces In vivo Bacterial Burden and Lung Lesions}

Bestatin has been used before as a low molecular immunomodulator. It exhibits antitumoral and antimicrobial activities through the activation of host defense mechanisms and shows low toxicity even after a long-term administration (Ota, 1991). In several mouse-model studies, effective and safe bestatin doses ranged from 0.1 to $10 \mathrm{mg} / \mathrm{kg}$ of body weight or in doses of 10-100 $\mu \mathrm{g}$ per animal (Bruley-Rosset et al., 1979; Carter et al., 2012; Reinhoudt et al., 2012; Lis et al., 2013). To test whether bestatin has any effect on tuberculosis progression, IFN- $\gamma$ knockout mice were infected with $10^{4} \mathrm{CFU}$ of $M$. tuberculosis $\mathrm{H} 37 \mathrm{Rv}$ and treated with the inhibitor at $1 \mathrm{mg} / \mathrm{kg} /$ day intranasally. After completion of therapy, bestatin reduced bacterial burden $(\sim 1.4 \mathrm{Log})$ in the lungs when compared to PBS administration and isoniazid corroborates the efficacy of treatment method (Figures 7A,B). Thus, bestatin inhibits up to $95.37 \%$ of $M$. tuberculosis growth in the mice lungs. In addition, treatment reduced lung lesions caused by infection (Figure 7C) from $9.09 \mathrm{~mm}^{2}$ of lung lesion area in PBS group to $2.46 \mathrm{~mm}^{2}$ in bestatin treated mice (Figure 7D). Taken together, our results indicate that bestatin is a promising drug and a model compound for anti-TB drugs.

\section{DISCUSSION}

Leucine aminopeptidases are known to play important roles in bacterial physiology and have not yet been characterized in many pathogenic bacteria, including $M$. tuberculosis. In this study we report the identification and biochemical characterization of the M. tuberculosis M17 family LAP as a cytosolic metal-dependent protease that shows high sensitivity to bestatin. In addition, M. tuberculosis in vitro growth and survival in macrophages had a significant bestatin dose-dependent reduction. Furthermore, bestatin treatment in murine tuberculosis model was useful in reducing both mycobacterial load in the lungs and tissue lesions caused the infection.

Aminopeptidases are widely distributed in animals, plants and microorganisms, and found in the extracellular millieu, cytoplasm, in many subcellular organelles and as components of membranes (Matsui et al., 2006). M17 protease members produced by a number of pathogenic organisms are currently under intense investigation. In some of these cases, the enzyme is secreted and act extracellularly. However, bacterial LAPs are most commonly found in the cytosol and generally act as homohexameric enzymes, while extracellular LAPs are functional as monomers (Gonzales and Robert-Baudouy, 1996). In agreement with literature, we found that the $M$. tuberculosis LAP is cytosolic (Figure 2B) and probably acts as an oligomer enzyme (Figure 2C) formed by six monomers (Figure 3). The enzyme could otherwise be secreted in vivo under specific physiological conditions.

Leucine aminopeptidases belong to the M17 family of metalloproteases, which mainly prefer $\mathrm{Zn}^{2+}$, while other aminopeptidases are dependent on $\mathrm{Mn}^{2+}, \mathrm{Fe}^{2+}$, or $\mathrm{Mg}^{2+}$. Like that of Staphylococcus aureus (Singh et al., 2012), M. tuberculosis LAP exhibits maximum activity in the presence of $\mathrm{Ni}^{2+}$, but it is active in the presence of a broad range of other metals (Figure 4A). The wide-ranging metal cofactor profile of LAP may allow its activity under different in vivo conditions, where some metals are limited and tightly regulated by both host and bacteria, resulting in an altered enzymatic activity under certain conditions (Kehl-Fie et al., 2011; Hood and Skaar, 2012). 
A

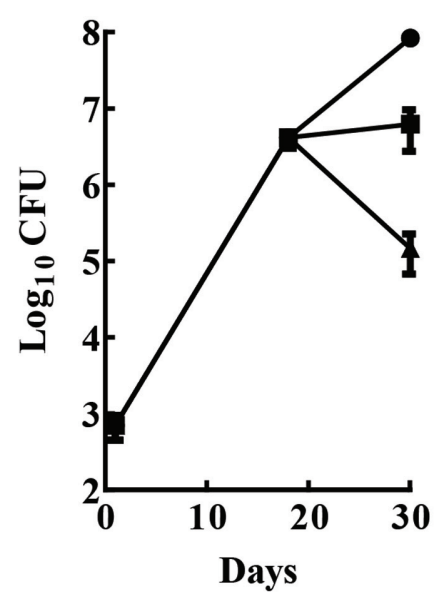

C

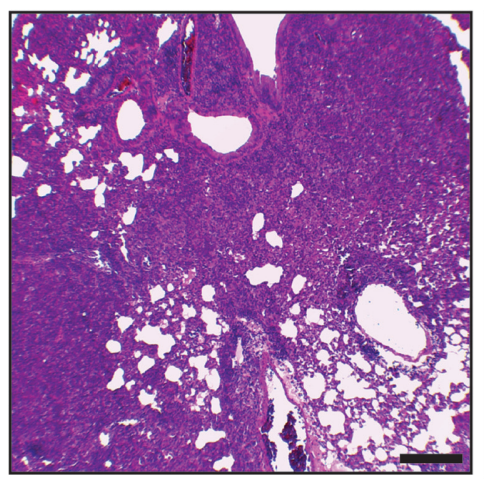

PBS

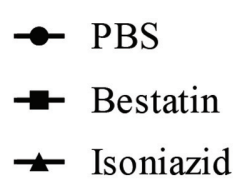

$\rightarrow$ Isoniazid

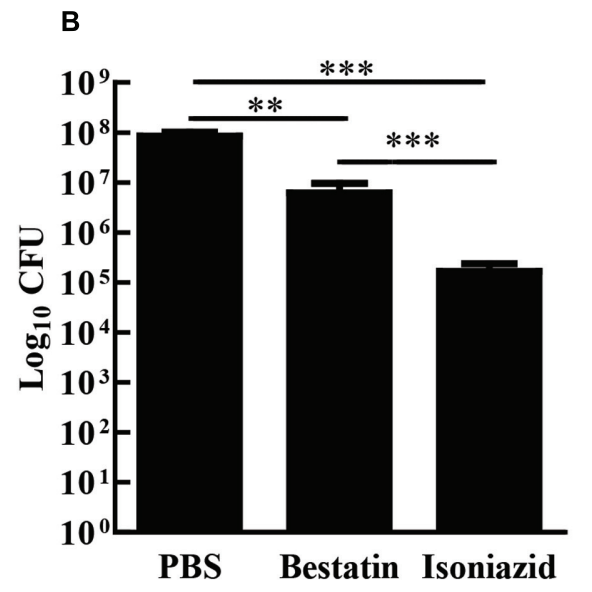

D
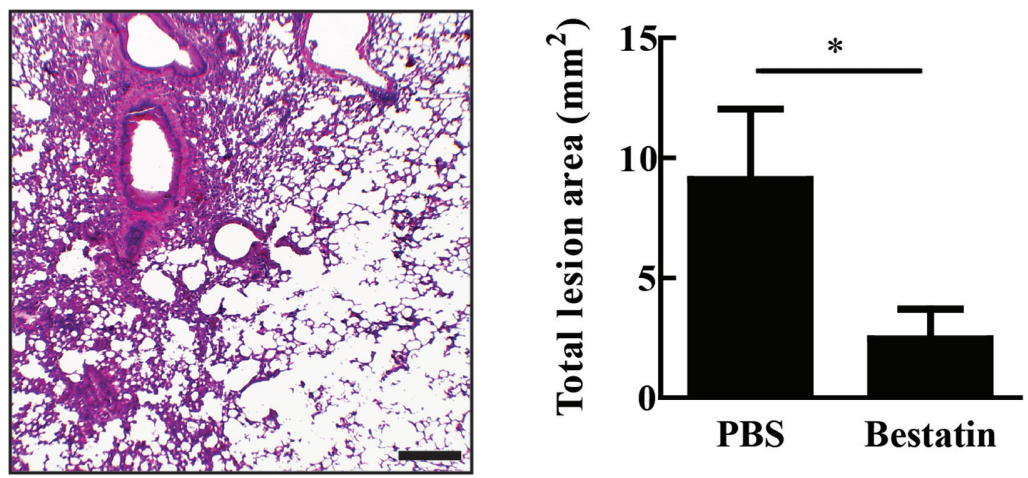

Bestatin

FIGURE 7 | Bestatin reduces in vivo $\mathbf{M}$. tuberculosis burden and lung lesion. (A) IFN- $\gamma \mathrm{KO}$ mice were intranasal infected with $10^{4}$ CFU of $M$. tuberculosis H37Rv. Eighteen days after infection, the mice were treated with bestatin at $1 \mathrm{mg} / \mathrm{kg}(\boldsymbol{\square})$ isoniazid $(\mathbf{\Delta})$ and control group of infected mice were treated with PBS $(\mathbf{O})$ The bacillary loads in the lungs were determined after euthanizing the mice at days 1, 18, and 28 post infections. (B) Comparison of lung CFU after treatment. (C) Representative lung sections (left bottom lobe) with HE stain of $M$. tuberculosis infected mice treated with PBS (left) or bestatin (right). Scale bars represent $200 \mu \mathrm{m}$. (D) Results of the quantification of the inflammatory lesion area sizes. Data shown represent mean $\pm \mathrm{SEM}, n=4$. ${ }^{*} p<0.05 ;{ }^{*} p<0.01$; ${ }^{* * *} p<0.001$; difference between groups by One-way ANOVA with Tukey's Multiple Comparison Test or $t$-test.

Despite conservation of amino acid sequences, M17 members show variable $\mathrm{pH}$ and temperature optima. Although MtLAP is active over a broad range of temperatures with optimal $55^{\circ} \mathrm{C}$, at physiological temperature the enzyme remains with high activity (Figure 4C). Moreover, its activity shows a marked dependence on neutral/alkaline $\mathrm{pH}$, since the enzyme is completely inactive at $\mathrm{pH} 5$ (Figure 4B). This correlates well with observations that recombinant members of M17 proteases assemble better into active oligomers at higher temperature and alkaline $\mathrm{pHs}$ (Matsui et al., 2006; Cadavid-Restrepo et al., 2011). Thus, the ability of $M$. tuberculosis to preserve intrabacterial $\mathrm{pH}$ inside phagosomal compartments (Vandal et al., 2008) provides an optimum environment for MtLAP function during infection. MtLAP does cleave substrates with charged side chains and shows preference for substrates with hydrophobic amino acids (Figure 4D). This substrate specificity profile supports future search for specific inhibitors of $M$. tuberculosis LAP, which could be used as new TB drugs.
Bestatin is a natural dipeptide analog product isolated from actinomycetes. It potently inhibits aminopeptidases, including LAP M17 family (Suda et al., 1976; Burley et al., 1991; Matsui et al., 2006), and MtLAP shows high sensitivity to this inhibitor (Figures 5A,B). Bestatin inhibited MtLAP enzymatic activity as well as $M$. tuberculosis in vitro growth, suggesting that MtLAP activity is associated to metabolism and physiology of the bacteria (Figure 6A). Moreover, bestatin has been shown to inhibit in vitro growth of S. aureus (Singh et al., 2012) and Babesia bovis (Aboge et al., 2015), as well as P. falciparum in mouse models of malaria (Nankya-Kitaka et al., 1998; Gavigan et al., 2001; Naughton et al., 2010). The reduction mediated by bestatin of bacterial burden and lung tissue lesions lead by infection, (Figure 7), suggests MtLAP may act not only in bacterial physiology but also in $M$. tuberculosis virulence. These results support further experiments to establish the role of MtLAP in the pathogenesis of TB. Bestatin is associated with immunomodulatory effects activating monocytes/macrophages 
and promoting the secretion of the pro-inflammatory cytokines IL-1, IL-6, IFN- $\gamma$, and TNF- $\alpha$, as well as the growth factors GM-CSF and G-SCF by immune system cells (Müller et al., 1982; Schorlemmer et al., 1983; Shibuya et al., 1987; Okamura et al., 1990). It has been demonstrated that bestatin can be administered to animals at very low toxicity and with multiple positive effects on the immune system. Those studies have also revealed beneficial effects on the survival of animals with some experimental tumors. Subsequent research in human patients have confirmed the immunomodulatory effects of bestatin and provided encouraging results on the potential of this drug in cancer treatments (Talmadge et al., 1986; Inoi et al., 1995). Bestatin is used as an immunomodulator and antitumor drug, under the trademark Ubenimex and various active stereoisomers and substituted analogs are commercially available as useful tools for in vitro and animal drug experimentation (Ota, 1991; Scornik and Botbol, 2001). Moreover, bestatin may have effects direct on bacteria and/or in modulation of host immune system leading to bacterial control. Thus, more studies are needed to establish whether bestatin mechanism of action actually correlates with mycobacterial proteins beyond LAP or even with host enzymes.

In toxicological studies, bestatin showed very low toxicity and no death occurred following the oral administration of the maximum dose capable of dosing such as $4 \mathrm{~g} / \mathrm{kg}$ for mice, $2 \mathrm{~g} / \mathrm{kg}$ for rats and $1.2 \mathrm{~g} / \mathrm{kg}$ for dog. General toxic signs seen in mice and rats following subcutaneous and intraperitonial injections were depression, suppressed movement, piloerection, inhibition of spontaneous movement, anorexia and emaciation (Sakakibara et al., 1983). In human clinical studies of bestatin, hematology, hepatic and renal function tests revealed no apparent adverse reactions and minimal side effects were noted chiefly comprising of reversible gastro-intestinal disturbances (Saito et al., 1983; Ikeda et al., 1985; Tsukagoshi, 1987; Ichinose et al., 2003). Although bestatin properties seem to be promising, pharmacokinetics could be an obstacle to its use as a TB drug. In mice, ${ }^{3} \mathrm{H}$-bestatin diffuses rapidly from the intravascular space into the extracellular fluid after its intravenous injection and from there most of the drug is eliminated in the urine (Scornik and Botbol, 1997). Furthermore, bestatin, orally administered, is efficiently absorbed by the intestinal brush border, whereas high concentrations of the drug in the serum are maintained only for a short time in mice because of its rapid elimination (Abe et al., 1989). Otherwise, urinary elimination is slower in humans (Ueda et al., 1994). Moreover, intrapulmonary delivery of isoniazid, capreomycin, or amikacin to mice has resulted in a better reduction of pulmonary mycobacterial loads than that seen by standard drug delivery methods when lower concentrations of drugs and fewer doses have been used (Gonzalez-Juarrero et al., 2012; Pham et al., 2015). Thus, in our study, intranasal administration of bestatin may have extended drug effects in the lungs, the main TB target organ,

\section{REFERENCES}

Abe, F., Alvord, G., Koyama, M., Matsuda, A., and Talmadge, J. E. (1989). Pharmacokinetics of bestatin and oral activity for treatment of experimental bypassing the problem of its rapid urinary elimination and thus showing efficacy to reduce $M$. tuberculosis loads in mice lungs. The bacterial counts in infected mice indicates that bestatin probably has in vivo bacteriostatic activity since it has maintained the pulmonary bacterial load constant during the time course of the treatment whereas isoniazid decreases the M. tuberculosis burden in the mice lungs (Figure 7A). Taking the above facts with our findings, bestatin or its analogs that show/have better pharmacokinetics could be promising drugs on TB treatment.

In summary, our results showed that $M$. tuberculosis produces an oligomeric cytosol LAPs that is a member of the M17 metalloprotease family. The activity of M. tuberculosis LAP is very sensitive to bestatin, a powerful aminopeptidase inhibitor. In addition, bestatin effects on mycobacterial growth and TB mice model infection highlight aminopeptidases as potential drug targets in tuberculosis.

\section{AUTHOR CONTRIBUTIONS}

Conceived and design the experiments: JdS and AC; Performed the experiments: AC and DN; Analyzed the data: AC, JdS, DN, and IB; Contributed reagents/materials/analysis tools: AJ-K, IB, $\mathrm{AK}, \mathrm{JdS}$; Wrote the manuscript draft: AC; Critically revised the manuscript: All authors.

\section{FUNDING}

This work was supported by $\mathrm{CNPq}$ (Conselho Nacional de Ciência e Tecnologia) grant number: 303675/2015-2 and 307186/2013-0. FAPDF (Fundação de Apoio à Pesquisa do Distrito Federal) grant numbers: 193.001.076/2015 and 193.000.822/2015. MCT/CNPq/FNDCT/FAPs/MEC/CAPES/PROCENTRO-OESTE.

\section{ACKNOWLEDGMENTS}

The authors thank Dr. Aline Carvalho Batista for the histopathology core facility at Faculdade de Odontologia from Universidade Federal de Goiás and LACEN-DF (Laboratório Central de Saúde Pública do Distrito Federal) for BLS-3 lab.

\section{SUPPLEMENTARY MATERIAL}

The Supplementary Material for this article can be found online at: http://journal.frontiersin.org/article/10.3389/fmicb. 2017.00504/full\#supplementary-material

metastases. Cancer Immunol. Immunother. 28, 29-33. doi: 10.1007/BF0020 5797

Aboge, G. O., Cao, S., Terkawi, M. A., Masatani, T., Goo, Y., AbouLaila, M., et al. (2015). Molecular characterization of Babesia bovis M17 leucine 
aminopeptidase and inhibition of Babesia growth by bestatin. J. Parasitol. 101, 536-541. doi: 10.1645/15-745.1

Acosta, D., Cancela, M., Piacenza, L., Roche, L., Carmona, C., and Tort, J. F. (2008). Fasciola hepatica leucine aminopeptidase, a promising candidate for vaccination against ruminant fasciolosis. Mol. Biochem. Parasitol. 158, 52-64. doi: 10.1016/j.molbiopara.2007.11.011

Bastos, I. M. D., Motta, F. N., Charneau, S., Santana, J. M., Dubost, L., Augustyns, K., et al. (2010). Prolyl oligopeptidase of Trypanosoma brucei hydrolyzes native collagen, peptide hormones and is active in the plasma of infected mice. Microbes Infect. 12, 457-466. doi: 10.1016/j.micinf.2010.02.007

Bhosale, M., Kadthur, J. C., and Nandi, D. (2012). Roles of Salmonella enterica serovar Typhimurium encoded peptidase N during systemic infection of Ifn $\gamma$-/mice. Immunobiology 217, 354-362. doi: 10.1016/j.imbio.2011.07.010

Bruley-Rosset, M., Florentin, I., Kiger, N., Schulz, J., and Mathé, G. (1979). Restoration of impaired immune functions of aged animals by chronic bestatin treatment. Immunology 38, 75-83.

Burley, S. K., David, P. R., and Lipscomb, W. N. (1991). Leucine aminopeptidase: bestatin inhibition and a model for enzyme-catalyzed peptide hydrolysis. Proc. Natl. Acad. Sci. U.S.A. 88, 6916-6920. doi: 10.1073/pnas.88.16.6916

Burley, S. K., David, P. R., Taylor, A., and Lipscomb, W. N. (1990). Molecular structure of leucine aminopeptidase at 2.7-A resolution. Proc. Natl. Acad. Sci. U.S.A. 87, 6878-6882. doi: 10.1073/pnas.87.17.6878

Cadavid-Restrepo, G., Gastardelo, T. S., Faudry, E., de Almeida, H., Bastos, I. M., Negreiros, R. S., et al. (2011). The major leucyl aminopeptidase of Trypanosoma cruzi (LAPTc) assembles into a homohexamer and belongs to the M17 family of metallopeptidases. BMC Biochem. 12:46. doi: 10.1186/1471-2091-12-46

Carroll, R. K., Robison, T. M., Rivera, F. E., Davenport, J. E., Jonsson, I.-M., Florczyk, D., et al. (2012). Identification of an intracellular M17 family leucine aminopeptidase that is required for virulence in Staphylococcus aureus. Microbes Infect. 14, 989-999. doi: 10.1016/j.micinf.2012.04.013

Carter, S. K., Umezawa, H., Douros, J., and Sakurai, Y. (2012). Antitumor Antibiotics. Berlin: Springer Science \& Business Media.

Correa, A. F., Bailao, A. M., Bastos, I. M. D., Orme, I. M., Soares, C. M. A., Kipnis, A., et al. (2014). Endothelin system has a significant role in the pathogenesis and progression of Mycobacterium tuberculosis infection. Infect. Immun. 82, 5154-5165. doi: 10.1128/IAI.02304-14

Flexner, C., Bate, G., and Kirkpatrick, P. (2005). Tipranavir. Nat. Rev. Drug Discov. 4, 955-956. doi: 10.1038/nrd1907

Frees, D., Brøndsted, L., and Ingmer, H. (2013). Bacterial proteases and virulence. Subcell. Biochem. 66, 161-192. doi: 10.1007/978-94-007-5940-4_7

Gavigan, C. S., Dalton, J. P., and Bell, A. (2001). The role of aminopeptidases in haemoglobin degradation in Plasmodium falciparum-infected erythrocytes. Mol. Biochem. Parasitol. 117, 37-48. doi: 10.1016/S0166-6851(01) 00327-9

Gonzales, T., and Robert-Baudouy, J. (1996). Bacterial aminopeptidases: properties and functions. FEMS Microbiol. Rev. 18, 319-344. doi: 10.1111/j.1574-6976. 1996.tb00247.x

Gonzalez-Juarrero, M., Woolhiser, L. K., Brooks, E., DeGroote, M. A., and Lenaerts, A. J. (2012). Mouse model for efficacy testing of antituberculosis agents via intrapulmonary delivery. Antimicrob. Agents Chemother. 56, 3957-3959. doi: 10.1128/AAC.00464-12

Grellier, P., Vendeville, S., Joyeau, R., Bastos, I. M., Drobecq, H., Frappier, F., et al. (2001). Trypanosoma cruzi prolyl oligopeptidase Tc80 is involved in nonphagocytic mammalian cell invasion by trypomastigotes. J. Biol. Chem. 276, 47078-47086. doi: 10.1074/jbc.M106017200

Günther, G. (2014). Multidrug-resistant and extensively drug-resistant tuberculosis: a review of current concepts and future challenges. Clin. Med. 14, 279-285. doi: 10.7861/clinmedicine.14-3-279

Hearn, A., York, I. A., and Rock, K. L. (2009). The specificity of trimming of MHC class I-presented peptides in the endoplasmic reticulum. J. Immunol. 183, 5526-5536. doi: 10.4049/jimmunol.0803663

Hood, M. I., and Skaar, E. P. (2012). Nutritional immunity: transition metals at the pathogen-host interface. Nat. Rev. Microbiol. 10, 525-537. doi: 10.1038/ nrmicro2836

Ichinose, Y., Genka, K., Koike, T., Kato, H., Watanabe, Y., Mori, T., et al. (2003). Randomized double-blind placebo-controlled trial of bestatin in patients with resected stage I squamous-cell lung carcinoma. J. Natl. Cancer Inst. 95, 605-610. doi: $10.1093 /$ jnci/95.8.605
Ikeda, S., Ishihara, K., and Taguchi, G. (1985). Phase III study of bestatin in patients with malignant skin tumors. (1) Malignant melanoma. Gan To Kagaku Ryoho 12, 77-85.

Ingmer, H., and Brøndsted, L. (2009). Proteases in bacterial pathogenesis. Res. Microbiol. 160, 704-710. doi: 10.1016/j.resmic.2009.08.017

Inoi, K., Goto, S., Nomura, S., Isobe, K., Nawa, A., Okamoto, T., et al. (1995). Aminopeptidase inhibitor ubenimex (bestatin) inhibits the growth of human choriocarcinoma in nude mice through its direct cytostatic activity. Anticancer Res. 15, 2081-2087.

Kehl-Fie, T. E., Chitayat, S., Hood, M. I., Damo, S., Restrepo, N., Garcia, C., et al. (2011). Nutrient metal sequestration by calprotectin inhibits bacterial superoxide defense, enhancing neutrophil killing of Staphylococcus aureus. Cell Host Microbe 10, 158-164. doi: 10.1016/j.chom.2011.07.004

Kennan, R. M., Wong, W., Dhungyel, O. P., Han, X., Wong, D., Parker, D., et al. (2010). The subtilisin-like protease AprV2 is required for virulence and uses a novel disulphide-tethered exosite to bind substrates. PLoS Pathog. 6:e1001210. doi: 10.1371/journal.ppat.1001210

Klemba, M., and Goldberg, D. E. (2002). Biological roles of proteases in parasitic Protozoa. Annu. Rev. Biochem. 71, 275-305. doi: 10.1146/annurev.biochem.71. 090501.145453

Konvalinka, J., Kräusslich, H.-G., and Müller, B. (2015). Retroviral proteases and their roles in virion maturation. Virology 47, 403-417. doi: 10.1016/j.virol.2015. 03.021

Lee, Y.-R., Na, B.-K., Moon, E.-K., Song, S.-M., Joo, S.-Y., Kong, H.-H., et al. (2015). Essential role for an M17 leucine aminopeptidase in encystation of Acanthamoeba castellanii. PLoS ONE 10:e0129884. doi: 10.1371/journal.pone. 0129884

Lenaerts, A. J. M., Gruppo, V., Brooks, J. V., and Orme, I. M. (2003). Rapid in vivo screening of experimental drugs for tuberculosis using gamma interferon genedisrupted mice. Antimicrob. Agents Chemother. 47, 783-785. doi: 10.1128/AAC. 47.2.783-785.2003

Lis, M., Szczypka, M., Suszko, A., and Obmiñska-Mrukowicz, B. (2013). The effects of bestatin on humoral response to sheep erythrocytes in non-treated and cyclophosphamide-immunocompromised mice. Immunopharmacol. Immunotoxicol. 35, 133-138. doi: 10.3109/08923973.2012.719524

Marcilla, A., De la Rubia, J. E., Sotillo, J., Bernal, D., Carmona, C., Villavicencio, Z., et al. (2008). Leucine aminopeptidase is an immunodominant antigen of fasciola hepatica excretory and secretory products in human infections. Clin. Vaccine Immunol. 15, 95-100. doi: 10.1128/CVI.00338-07

Master, S. S., Rampini, S. K., Davis, A. S., Keller, C., Ehlers, S., Springer, B., et al. (2008). Mycobacterium tuberculosis prevents inflammasome activation. Cell Host Microbe 3, 224-232. doi: 10.1016/j.chom.2008.03.003

Matsui, M., Fowler, J. H., and Walling, L. L. (2006). Leucine aminopeptidases: diversity in structure and function. Biol. Chem. 387, 1535-1544. doi: 10.1515/ BC. 2006.191

McGowan, S., Oellig, C. A., Birru, W. A., Caradoc-Davies, T. T., Stack, C. M., Lowther, J., et al. (2010). Structure of the Plasmodium falciparum M17 aminopeptidase and significance for the design of drugs targeting the neutral exopeptidases. PNAS 107, 2449-2454. doi: 10.1073/pnas.0911813107

Müller, W. E. G., Schuster, D. K., Zahn, R. K., Maidhof, A., Leyhausen, G., Falke, D., et al. (1982). Properties and specificity of binding sites for the immunomodulator bestatin on the surface of mammalian cells. Int. J. Immunopharmacol. 4, 393-400. doi: 10.1016/0192-0561(82)90012-1

Naamati, A., Regev-Rudzki, N., Galperin, S., Lill, R., and Pines, O. (2009). Dual targeting of Nfs1 and discovery of its novel processing enzyme, Icp55. J. Biol. Chem. 284, 30200-30208. doi: 10.1074/jbc.M109.034694

Nankya-Kitaka, M. F., Curley, G. P., Gavigan, C. S., Bell, A., and Dalton, J. P. (1998). Plasmodium chabaudi chabaudi and P. falciparum: inhibition of aminopeptidase and parasite growth by bestatin and nitrobestatin. Parasitol. Res. 84, 552-558. doi: 10.1007/s004360050447

Naughton, J. A., Nasizadeh, S., and Bell, A. (2010). Downstream effects of haemoglobinase inhibition in Plasmodium falciparum-infected erythrocytes. Mol. Biochem. Parasitol. 173, 81-87. doi: 10.1016/j.molbiopara.2010. 05.007

Okamura, S., Omori, F., Haga, K., Baba, H., Sugimachi, K., and Niho, Y. (1990). Influence of bestatin on production of granulocyte-macrophage colonystimulating factor from human peripheral blood mononuclear cells in vitro. Acta Oncol. 29, 795-797. doi: 10.3109/02841869009093002 
Ota, K. (1991). Review of ubenimex (Bestatin): clinical research. Biomed. Pharmacother. 45, 55-60. doi: 10.1016/0753-3322(91)90123-B

Pham, D.-D., Fattal, E., and Tsapis, N. (2015). Pulmonary drug delivery systems for tuberculosis treatment. Int. J. Pharm. 478, 517-529. doi: 10.1016/j.ijpharm. 2014.12.009

Rawlings, N. D., and Barrett, A. J. (1993). Evolutionary families of peptidases. Biochem. J. 290, 205-218. doi: 10.1042/bj2900205

Reinhoudt, D. N., Connors, T. A., Pinedo, H. M., and van de Poll, K. W. (2012). Structure-Activity Relationships of Anti-Tumour Agents. Berlin: Springer Science \& Business Media.

Ribeiro-Guimarães, M. L., and Pessolani, M. C. V. (2007). Comparative genomics of mycobacterial proteases. Microb. Pathog. 43, 173-178. doi: 10.1016/j.micpath. 2007.05.010

Roberts, D. M., Personne, Y., Ollinger, J., and Parish, T. (2013). Proteases in Mycobacterium tuberculosis pathogenesis: potential as drug targets. Future Microbiol. 8, 621-631. doi: 10.2217/fmb.13.25

Saito, K., Miyasato, H., Tajima, K., and Ikeda, S. (1983). Phase I study of Bestatin: (I) A clinical study on determination of an optimal dose of Bestatin. Gan To Kagaku Ryoho 10, 211-217.

Sakakibara, T., Ito, K., Irie, Y., Hagiwara, T., Sakai, Y., Hayashi, M., et al. (1983). Toxicological studies on bestatin. I. Acute toxicity test in mice, rats and dogs. Jpn. J. Antibiot. 36, 2971-2984.

Savijoki, K., Ingmer, H., and Varmanen, P. (2006). Proteolytic systems of lactic acid bacteria. Appl. Microbiol. Biotechnol. 71, 394-406. doi: 10.1007/s00253006-0427-1

Schorlemmer, H. U., Bosslet, K., and Sedlacek, H. H. (1983). Ability of the immunomodulating dipeptide bestatin to activate cytotoxic mononuclear phagocytes. Cancer Res. 43, 4148-4153.

Scornik, O. A., and Botbol, V. (1997). Cellular uptake of 3H-bestatin in tissues of mice after its intravenous injection. Drug Metab. Dispos. 25, 798-804.

Scornik, O. A., and Botbol, V. (2001). Bestatin as an experimental tool in mammals. Curr. Drug Metab. 2, 67-85. doi: 10.2174/1389200013338748

Shibuya, K., Hayashi, E., Abe, F., Takahashi, K., Horinishi, H., Ishizuka, M., et al. (1987). Enhancement of interleukin 1 and interleukin 2 releases by ubenimex. J. Antibiot. 40, 363-369. doi: 10.7164/antibiotics. 40.363

Singh, A. K., Singh, R., Tomar, D., Pandya, C. D., and Singh, R. (2012). The leucine aminopeptidase of Staphylococcus aureus is secreted and contributes to biofilm formation. Int. J. Infect. Dis. 16, e375-e381. doi: 10.1016/j.ijid.2012.01.009

Skinner-Adams, T. S., Stack, C. M., Trenholme, K. R., Brown, C. L., Grembecka, J., Lowther, J., et al. (2010). Plasmodium falciparum neutral aminopeptidases: new targets for anti-malarials. Trends Biochem. Sci. 35, 53-61. doi: 10.1016/j.tibs. 2009.08.004
Suarez, C., Volkmann, K., Gomes, A. R., Billker, O., and Blackman, M. J. (2013). The malarial serine protease SUB1 plays an essential role in parasite liver stage development. PLoS Pathog. 9:e1003811. doi: 10.1371/journal.ppat.1003811

Suda, H., Aoyagi, T., Takeuchi, T., and Umezawa, H. (1976). Inhibition of aminopeptidase $\mathrm{B}$ and leucine aminopeptidase by bestatin and its stereoisomer. Arch. Biochem. Biophys. 177, 196-200. doi: 10.1016/0003-9861(76)90429-X

Talmadge, J. E., Lenz, B. F., Pennington, R., Long, C., Phillips, H., Schneider, M., et al. (1986). Immunomodulatory and therapeutic properties of bestatin in mice. Cancer Res. 46, 4505-4510.

Tsukagoshi, S. (1987). A new antitumor drug with immunomodulating activity, ubenimex (bestatin). Gan To Kagaku Ryoho 14, 2385-2391.

Ueda, T., Tohyama, K., Wano, Y., Tsutani, H., Fukushima, T., Iwasaki, H., et al. (1994). Pharmacokinetic and clinical pilot study of high-dose intermittent ubenimex treatment in patients with myelodysplastic syndrome. Anticancer Res. 14, 2093-2097.

Vandal, O. H., Pierini, L. M., Schnappinger, D., Nathan, C. F., and Ehrt, S. (2008). A membrane protein preserves intrabacterial $\mathrm{pH}$ in intraphagosomal Mycobacterium tuberculosis. Nat. Med. 14, 849-854. doi: 10.1038/nm.1795

WHO (2016). Global Tuberculosis Report. Available at: http://www.who.int/tb/ publications/global_report/en/ [accessed December 21, 2016].

$\mathrm{Xu}$, J., Baldwin, D., Kindrachuk, C., and Hegedus, D. D. (2006). Serine proteases and metalloproteases associated with pathogenesis but not host specificity in the Entomophthoralean fungus Zoophthora radicans. Can. J. Microbiol. 52, 550-559. doi: 10.1139/w06-004

Yike, I. (2011). Fungal proteases and their pathophysiological effects. Mycopathologia 171, 299-323. doi: 10.1007/s11046-010-9386-2

Zhang, L., Jia, Y., Wang, L., and Fang, R. (2007). A proline iminopeptidase gene upregulated in planta by a LuxR homologue is essential for pathogenicity of Xanthomonas campestris pv. campestris. Mol. Microbiol. 65, 121-136. doi: 10.1111/j.1365-2958.2007.05775.x

Conflict of Interest Statement: The authors declare that the research was conducted in the absence of any commercial or financial relationships that could be construed as a potential conflict of interest.

Copyright (c) 2017 Correa, Bastos, Neves, Kipnis, Junqueira-Kipnis and de Santana. This is an open-access article distributed under the terms of the Creative Commons Attribution License (CC BY). The use, distribution or reproduction in other forums is permitted, provided the original author(s) or licensor are credited and that the original publication in this journal is cited, in accordance with accepted academic practice. No use, distribution or reproduction is permitted which does not comply with these terms. 